
review. Journal of Education, Health and Sport. 2022;12(2):122-130. eISSN 2391-8306. DOI http://dx.doi.org/10.12775/JEHS.2022.12.02.014

https://apcz.umk.pl/JEHS/article/view/JEHS.2022.12.02.014

https://zenodo.org/record/6026049

The journal has had 40 points in Ministry of Education and Science of Poland parametric evaluation. Annex to the announcement of the Minister of Education and Science of December 21, 2021. No. 32343. Has a Journal's Unique Identifier: 201159. Scientific disciplines assigned: Physical Culture Sciences (Field of Medical sciences and health sciences); Health Sciences (Field of Medical Sciences and Health Sciences).

Punkty Ministerialne z 2019 - aktualny rok 40 punktów. Zalącznik do komunikatu Ministra Edukacji i Nauki z dnia 21 grudnia 2021 r. Lp. 32343. Posiada Unikatowy Identyfikator Czasopisma: 201159. Przypisane dyscypliny naukowe:Nauki o kulturze fizycznej (Dziedzina nauk medyczyych i nauk o zdrowiu); Nauki o zdrowiu (Dziedzina nauk medycznych i nauk o zdrowiu).

(c) The Authors 2022;

This article is published with open access at Licensee Open Journal Systems of Nicolaus Copernicus University in Torun, Poland

Open Access. This article is distributed under the terms of the Creative Commons Attribution Noncommercial License which permits any noncommercial use, distribution, and reproduction in any medium,

provided the original author (s) and source are credited. This is an open access article licensed under the terms of the Creative Commons Attribution Non commercial license Share alike.

(htp:/lo The authors declare that there is no conflict of interests regarding the publication of this paper.

Received: 26.01.2022. Revised: 26.01.2022. Accepted: 09.02.2022.

\title{
Late diagnosis of posterior urethral valves: a case report and the literature review
}

\section{Tomasz Szawłoga ${ }^{1}$, Aleksandra Sobieszczańska-Droździel ${ }^{2}$}

${ }^{1}$ Student's Scientific Group at the Department of Pediatric Nephrology, Medical University of Lublin, Poland

${ }^{2}$ Department of Pediatric Nephrology, Medical University of Lublin, Poland

Aleksandra Sobieszczańska-Droździel https://orcid.org/0000-0003-2702-5083 , aleksandra.sobieszczanska-drozdziel@umlub.pl

Tomasz Szawłoga https://orcid.org/0000-0002-4025-9813 tomasz.w.szawloga@gmail.com

\begin{abstract}
Posterior urethral valves (PUV) are the most common cause of lower urinary tract obstruction in boys. They are usually suspected antenatally or soon after the birth as the cause of severe hydronephrosis, oligohydramnios, renal hypodysplasia, and kidney failure. In milder forms of PUV, the uncharacteristic symptoms occur later in childhood, adolescence, or even adulthood and cause diagnostic problems. The final diagnosis and causative treatment of PUV are possible due to cystourethroscopy. Nevertheless, as a consequence of the defect, valve bladder syndrome (VBS) occurs and requires long-term treatment.

The authors present a case of a 14-year-old boy with a late diagnosis of PUV at the age of 7. Recurrent pyelonephritis and nonspecific voiding dysfunction were the first symptoms. Ultrasounds(US) were initially normal while videocystometry(VCM) showed the $3^{\text {rd }}$-grade right-sided vesicoureteral reflux (VUR), bladder diverticulum as well as discrete detrusor overactivity, and reduced bladder capacity without any signs of bladder obstruction. Bilateral post-inflammatory nephropathy completed the clinical picture. In urethrocystoscopy surprisingly PUV were found and incised. Due to recurrent urinary tract infections (UTIs) one year later the STING procedure was performed which resulted in the resolution of VUR. Despite this, the features of bladder dysfunction, requiring regular urodynamic evaluation and pharmacotherapy, persisted.

Recurrent UTIs in boys may suggest urinary tract obstruction and PUV should be considered regardless of the patient's age. Early diagnosis and appropriate management may improve the prognosis.
\end{abstract}

Key words: posterior urethral valves, vesicoureteral reflux, urinary tract infections 


\section{Introduction}

Posterior urethral valves (PUV) are congenital obstructing membranous folds within the lumen of the posterior urethra. They are the prevailing cause of lower urinary tract obstruction in boys with incidence ranging from 1:5000 to 1:8000 males [1].

PUV etiology is currently unknown however some authors suggest that they are the result of the abnormal insertion of the mesonephric duct into the urogenital sinus [2]. A possibility of genetic predisposition is considered. Talabi and Burtett reported cases of PUV at non-twin siblings $[3,4]$.

The main consequences of urethra obstruction caused by PUV are detrusor hypertrophy, urinary bladder wall trabeculation, and ureterohydronephrosis. All of these problems may lead to VUR, obstructive nephropathy, chronic pyelonephritis, and chronic kidney disease (CKD) [5] in $20-65 \%$ of all cases of which $8-21 \%$ will progress to end-stage renal disease (ESRD) $[6,7]$.

PUV are usually suspected on the routine prenatal US showing dilation of the posterior urethra, thickening of the urinary bladder wall ("keyhole" sign), and upper urinary tract dilation (megaureters and hydronephrosis). Every male child with such findings should be considered to have PUV until proven otherwise [8].

In cases of PUV with manifestation in infancy and early childhood, the symptoms may vary depending on the severity of the obstruction they cause. Patients often have UTIs, poor urine stream, voiding problems, or even acute kidney injury [9].

The only causative treatment is urethrocystoscopy which confirms the presence of the urethral valves, identifies their type, and enables ablation[8].

Case history

We present a 14-year-old boy with a delayed diagnosis of PUV at the age of 7 . The boy was born at 38 week of pregnancy from gravida 3 para 2 with a weight of $4700 \mathrm{~g}\left(99^{\text {th }}\right.$ percentile), length of $53 \mathrm{~cm}\left(95^{\text {th }}\right.$ percentile), and 10 points on Apgar scale. Cesarean section was performed due to high maternal fever and premature rupture of membranes with unknown origin at $31^{\text {st }}$ week. The prenatal US were normal.

At the age of 3, the boy showed a reluctance to use the toilet and still preferred diapers. $\mathrm{He}$ also presented daytime urinary incontinence during playtime possibly connected with holding ofthe urine. Parents and a general practitioner (GP) considered it normal for the boy's age. When the boy was 6 he suffered from a prolonged fever diagnosed by GP as an upper respiratory tract infection and treated with amoxicillin for about 3 months. Finally, the patient was admitted to our Department of Pediatric Nephrology, where acute pyelonephritis was diagnosed and successfully cured with cefuroxime axetil.

Subsequently, nephrological diagnostics were carried out. Uroflowmetry was irrelevant while VCM showed the $3^{\text {rd }}$-grade right-sided VUR, bladder diverticulum, and posterior urethral dilatation(Fig. 1) as well as reduction of bladder capacity in a sitting position+(70 $\mathrm{ml})$, and hyperreactivity of the detrusor. 


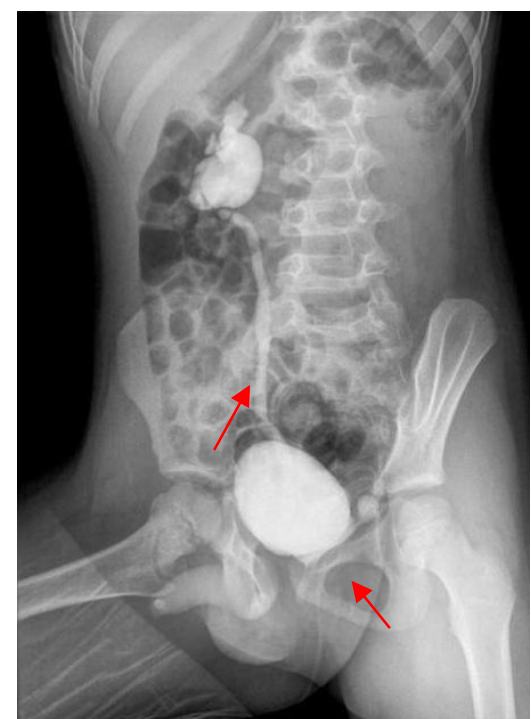

Figure 1. Videocystomety in patient with PUV at the age of 6 . Note the $3^{\text {rd }}$-grade right-sided VUR and bladder diverticulum - arrows (Department of Pediatric Radiology, Medical University of Lublin)

Due to those findings,furazidin prophylaxis $(2 \mathrm{mg} / \mathrm{kg}$ in the evening) and oxybutynin $(3 \mathrm{x} 2,5$ $\mathrm{mg}$ ) treatment were started.

In renal scintigraphy, bilateral post-inflammatory nephropathy signs with mild defects in radiotracer uptake in the renal parenchyma were found, more severe in the right kidney. Relative renal function was $61,8 \%$ and $38,2 \%$ in the left and right kidney respectively.

On the follow-up VCM, reduction of VUR to $2^{\text {nd }}$-grade and persistence of bladder dysfunction were found. Consequently, the patient was referred to the urologist, and the proper diagnosis was made only during urethrocystoscopy where quite surprisingly the $1^{\text {st }}$ type of PUV were found and incised. Uroflowmetry revealed the improvement in urinary flow, nevertheless, UTIs still occurred.

One year later the bladder capacity was still below the norm with the presence of involuntary detrusor contractions however there was no urine retention after micturition. $2^{\text {nd }}$-grade rightsided VUR persisted but there was no visible bladder diverticulum. Second scintigraphy showed progression of renal scarring and urine retention in the enlarged pelvicalyceal system of the right kidney. Later TENS (transcutaneous electrical nerve stimulation) was introduced and oxybutynin was replaced with doxazosin at a daily dose of $2 \mathrm{x} 1 \mathrm{mg}$. Due to unsatisfactory improvement, a decision to perform the right side STING (subureteric transurethral injection) procedure was made.

Afterward resolution of VUR (Fig. 2) and bladder overactivity were achieved. 


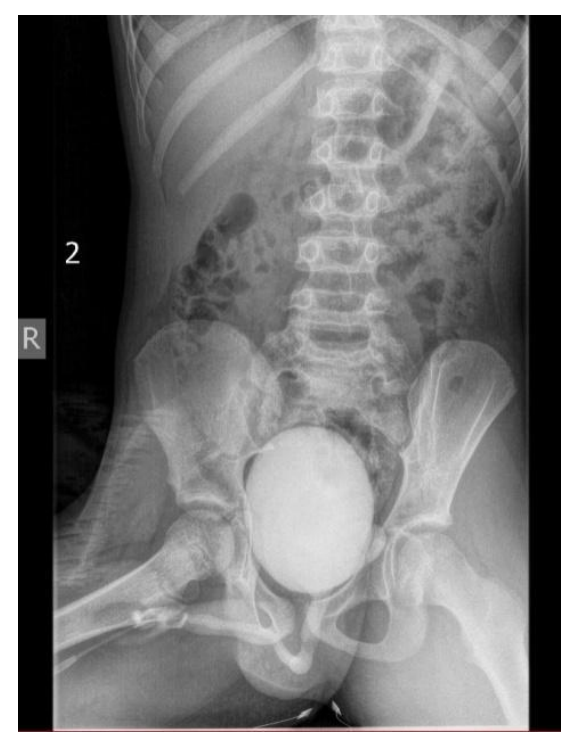

Figure 2. Videocystometry afterSTING procedure in the presented patient at the age of 8 . Note the resolution of VUR (Department of Pediatric Radiology, Medical University of Lublin)

There were neither incidences of bedwetting nor daytime urinary incontinence unless the patient was holding the urine.

In the following years, US and uroflowmetry were systematically performed and pharmacological treatment was continued. The patient constantly showed a tendency to hold the urine, which resulted in daytime urine incontinence, although UTIs occurred significantly less often. Interestingly, the bladder capacity considerably increased and after night the patient urinated large portions of even up to $700 \mathrm{ml}$.

At the age of 11 renal US showed right kidney pelvis dilation (AP 22mm) and micro-deposits in the bladder. Consequently, the assessment of metabolic risk factors of urolithiasis was performed and revealed hypercalciuria $(4,61 \mathrm{mg} / \mathrm{kg} / 24$ hours $)$ without any other abnormalities. Family history for urolithiasis was positive (mother and grandmother on the mother side). Preventive fluid and dietary therapies were introduced. In subsequent US pelvicalyceal system of the right kidney was enlarged and deformed without visible concernments neither in the kidneys nor in the bladder (Fig. 3).

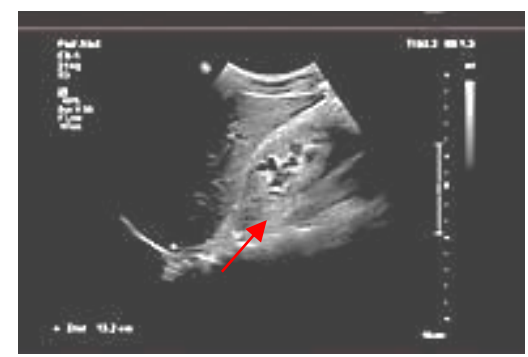

Figure 3. Ultrasounds of the right kidney in the presented patient at the age of 14 . Note moderately dilated and slightly deformed pelvicalyceal system (calyces' width up to $9 \mathrm{~mm}$, AP pelvis size $18 \mathrm{~mm}$ ) - arrows (Department of Pediatric Radiology, Medical University of Lublin)

Actually, at the age of 14, the patient has a normal renal function (e-GFR 131,5 $\left.\mathrm{ml} / \mathrm{min} . / 1.73 \mathrm{~m}^{2}\right)$, hypercalciuria $(5 \mathrm{mg} / \mathrm{kg} / 24$ hours), and the features of bladder dysfunction requiring regular uroflowmetry and pharmacotherapy with doxazosin in a daily dose of $2 \mathrm{mg}$ 
although significant improvement in the bladder emptying is noticeable (bladder capacity 320 $\mathrm{ml}$ ) and UTIs occur only occasionally.

\section{Discussion}

PUV are an important reason of bladder obstruction in males and manifest along a wide spectrum of age and severity, ranging from lethal disease to milder conditions revealed later in life. The most typical presentation for PUV is the detection of hydronephrosis in routine prenatal US, with subsequent definitive diagnosis after the birth. In the presented patient fetal US showed nothing significant and premature rupture of the membranes did not seem to be related to PUV. While 50-70\% of PUV are diagnosed in the first year of life, almost $25-50 \%$ can be seen neonatally [10]. According to the literature PUV diagnosis, made like in our patient after the $7^{\text {th }}$ year of life, is quite unusual. In an Australian retrospective study, $80 \%$ of postnatally diagnosed cases were detected by infancy due to UTIs or other genitourinary symptoms. Only 3 of 71 patients were diagnosed after the age of 5 years [11]. Talabi et al. reported only $24 \%$ cases of PUV diagnosed after infancy and only one after the age of 5 years, with a median age of 5 months [1]. Tambo et al. reported the median age of diagnosis 22 months [12] whereas Petersen et al. found only 12 cases $(6.6 \%)$ of patients with PUV diagnosed over the $5^{\text {th }}$ year of life throughout 28 years [13]. Reports of later diagnosis of PUV are rare and in adulthood, PUV are reported sporadically $[14,15]$.

UTIs are very common in PUV patients with an incidence of $50-60 \%[9,11,13,16,17]$. In the presented patient it was the reason for hospitalization in our Department. Pre-existing feverish conditions diagnosed as respiratory tract infections could be a symptom of undiagnosed UTIs. Diagnosis of UTI in the boy was the cause of further diagnostics including VCM, which revealed the presence of the unilateral $3^{\text {rd }}$-grade of VUR and dilated urethra. VUR as PUV complication is present in about half of all diagnosed cases and mostly, like in our patient, occurs unilaterally [18]. Dilated urethra might suggest PUV although performed in our patient urodynamic studies did not suggest the presence of obstruction but overactivity and reduction of bladder capacity. Consequently, anticholinergics (oxybutynin) and furazidine prophylaxis were introduced. Anticholinergics can improve bladder compliance and decrease voiding pressure [19]. Interestingly unilateral VUR by pressure pop-off mechanism helps in maintaining the function of the non-refluxing kidney by lowering the pressure in the bladder[20]. In the presented patient, that compensation mechanism was probably responsible for the lack of bladder obstruction features in urodynamic studies.

Unfortunately, the treatment did not bring a satisfactory improvement, and a subsequent VCM showed the persistence of VUR, although of a lower $\left(2^{\text {nd }}\right)$ degree, resolution of bladder diverticulum, and the persistence of the bladder dysfunction. Second scintigraphy showed progression of renal scarring and urine retention in the enlarged pelvicalyceal system. Due to ineffective treatment doxazosin was included. Alpha-adrenergic blockade can be used to relieve secondary bladder neck obstruction before and after PUV ablation [21]. Additionally, there were no reports of serious side effects associated with $\alpha$-blockers treatment in children [22].

On the follow-up colonization with Pseudomonas aeruginosa and relapses of UTIs occurred. Only $7-10 \%$ of all UTIs in children are caused by Pseudomonas aeruginosa [23], which often occurs in patients with CACUT (congenital malformations of the kidneys and urinary tract) including PUV [24]. In this contexts, it is not surprising that it was found in the presented patient. Additionally, previous long-term treatment with amoxicillin with subsequent cefuroxime axetil and prophylaxis with furazidine in our Department could have eradicated other bacteria, including the most common Escherichia coli. In the presented patient, 7 hectic episodes of UTIs, initially caused by Pseudomonas aeruginosa and later, after antipseudomonas vaccination by Escherichia coli, were diagnosed and treated.Permanent renal 
scarring is an obvious consequence of recurrent febrile UTIs, so signs of bilateral postinflammatory nephropathy in renal scintigraphy of our patient may indicate a previous history of UTIs that were not properly diagnosed. Renal scarring is observed as a result of febrile UTIs in $15-60 \%$ of affected children [25] and it is significantly higher in children with highgrade VUR $\left(3^{\text {rd }}-5^{\text {th }}\right)$ similar to that in our patient case[26].

Although US, voiding cystography, and urodynamic studies are valuable diagnostic procedures the final diagnosis and causal treatment of PUV is possible due to endoscopy. In the presented patient during urethrocystoscopy, performed at the age of 7, PUV were revealed and incised. PUV were categorized by Young in 1919 into 3 types: the most common type I (95\%), where folds originate from the distal edge of colliculus, type II of only historical significance, and type III (5\%) with the worst prognosis, where membrane with a central hole is not linked with colliculus [5]. In the presented patient the most common type I of PUV was diagnosed, which is not surprising in the context of the relatively mild clinical presentation. Unfortunately, cutting the valves does not cure the patient. After PUV ablation voiding patterns are similar to these before removal of an anatomical obstruction[20]. Permanent bladder dysfunction is reported in about $70-75 \%$ of affected boys [27] and was described by Mitchell in 1982 as valve bladder syndrome (VBS). It is a combination of persistent dilatation of the upper urinary tract, hypertrophy of the bladder walls, VUR, and hydronephrosis. The bladder changes go through three sequential stages: hypertrophy, compensation, and decompensation [28]. In the first one, due to the problems with bladder contraction and generation of the increased pressure, mechanical stress activates signals that mediate hypertrophy. This rapid increase of bladder mass and capacity helps with bladder emptying but voiding pressure is higher. In the second compensated phase, due to the changes in the smooth muscle and collagen distribution, the bladder demonstrates lower contractile capacity. One of the therapeutic options may be partial bladder denervation, reversible after obstruction removal. The last - decompensation phase is a progressive increase in bladder capacity with decreased incompliance, contractility. and ability to empty[29]. Such changes are the risk factors of dilatation of the upper urinary tract and kidney failure. VBS in urodynamic studies presents as bladder overactivity, poor compliance, and myogenic failure[5]. All of these symptoms may be found in subsequent urodynamic studies in the presented patient consequently leading to dilatation and deformation of the pelvicalyceal system of the right kidney in the last US.

Incidences of each dysfunction of the bladder are various in different authors'reports, which is probably connected with the patient's age at the time of evaluation [27]. Similarly in experimental models duration of every phase varies in different studies and is unpredictable[28]. Finding the right pattern of constantly changing bladder dysfunction is important to introduce the proper treatment so regular follow-up is essential. Pharmacological treatment, like in our patient, can be supported by TENS, which also may improve the outcome and enables to reduce the pharmacological treatment [30].

As VUR is one of the predisposition factors for infection [31], recurrent UTIs in the presented patient,prompted us to perform, a year after PUV ablation, the STING procedure, which resulted in the resolution of VUR and relief of UTIs.

The prognosis in patients with late diagnosis of PUV is uncertain. Bladder myogenic failure causes incomplete emptying and overflow urine incontinence. Then clean intermittent catheterization (CIC) may be recommended. However, boys with PUV meet a compliance problem secondary to a preserved sensitivity of the urethra [32]. The Mitrofanoff procedure (appendicovesicostomy) can be useful and leads to the improvement in the patient's compliance, reduction of hydronephrosis, bladder dysfunction, and capacity. However, despite the treatment, about $35 \%$ of patients will develop ESRD [33]. 
To date, only a few retrospective studies were performed where bladder stones were found as PUV complication [7,16,24]. However, according to the European Association of Urology guidelines VUR and ureteral stricture are high-risk factors for stone formation[34]. There is also a possible association between urolithiasis and recurrent infections caused by E.coli which can stimulate the growth of calcium oxalate - predominant component of kidney stones [35,36]. Additionally, the presented patient has a metabolic predisposition for urolithiasis, as hypercalciuria was diagnosed due to suspicion of bladder deposits in US. Actually, supportive treatment is sufficient and follow-up US did not reveal any signs of urolithiasis nevertheless regular evaluation is necessary.

Summary

The presented patient is an example of a late diagnosis of PUV. In cases of fever of unknown origin, urine analysis should be considered. Recurrent UTIs, especially in boys, may suggest urinary tract obstruction and PUV should be taken into account regardless of the patient's age. Although the US, uroflowmetry, VCM, and voiding cystography are valuable diagnostic procedures the final diagnosis and causative treatment of PUV are possible due to cystourethroscopy. Diagnosis of PUV means the necessity of long-term follow-up and the high risk of chronic kidney disease.

Statement of Ethics

The written informed consent to publish the case with accompanying images was obtained from the affected patient's mother.

Conflict of Interest Statement

The authors have no conflicts of interest to declare.

\section{References}

1. Talabi AO, Sowande OA, Etonyeaku AC, Salako AA, Adejuyigbe O; Posterior Urethral Valves in Children: Pattern of Presentation and Outcome of Initial Treatment in Ile-Ife, Nigeria. Niger J Surg. 2015;21(2):151-6.

2. Livne PM, Delaune J, Gonzales ET Jr; Genetic etiology of posterior urethral valves. J Urol. 1983;130:781-4.

3. Talabi A, Sowande O, Adejuyigbe O, Owa J, Igwe A; Posterior urethral valves in fraternal twins, case report and review of the literature. Ann. Pediatr. Surg: 2018;14:190191.

4. Burttet LM, Rosito TE, Nabinger GB, Berger M, Neto BS; Posterior urethral valves disorder in non-twin siblings: case report and literature review. Med Surg Urol 2014;3

5. Polak-Jonkisz D, Rehan LR, Fornalczyk K, Hackemer P, Zwolińska D; Valve bladder syndrome in children: On the trail of the best strategies to prevent chronic kidney disease. Adv Clin Exp Med. 2017;26(8):1293-1300.

6. Coquillette M, Lee RS, Pagni SE, Cataltepe S, Stein DR; Renal outcomes of neonates with early presentation of posterior urethral valves: a 10 -year single center experience. $\mathrm{J}$ Perinatol. 2020;40:112-117

7. Bilgutay AN, Roth DR, Gonzales ET Jr, Janzen N, Zhang W, Koh CJ, Gargollo P, Seth A; Posterior urethral valves: Risk factors for progression to renal failure. J Pediatr Urol. 2016;12(3):179.e1-7.

8. Fishberg S, Landau E, Duvdevani M, Gofrit O, Friedman S, Hidas G; Posterior Urethral Valves: Prenatal, Neonatal, and Long-Term Management. NeoReviews 2018; 19:e753-e761

9. Orumuah AJ, Oduagbon OE; Presentation, management, and outcome of posterior urethral valves in a Nigerian tertiary hospital. Afr J Paediatr Surg. 2015;12:18-22

10. Hodges SJ, Patel B, McLorie G, Atala A;Posterior urethral valves. ScientificWorldJournal. 2009;9:1119-26. 
11. Thakkar D, Deshpande AV, Kennedy SE; Epidemiology and demography of recently diagnosed cases of posterior urethral valves. Pediatr Res, 2014;76:560-563

12. Tambo FFM, Tolefac PN, Ngowe MN, Minkande JZ, Mbouche L, Guemkam G, Telelen NA, Angwafo FF 3rd, Sosso AM; Posterior urethral valves: 10 years audit of epidemiologic, diagnostic and therapeutic aspects in Yaoundé gynaeco-obstetric and paediatric hospital. BMC Urol. 2018;18:46.

13. Petersen KL, Moore DP, Kala UK; Posterior urethral valves in South African boys: Outcomes and challenges. S Afr Med J. 2018;108:667-670.

14. Kilciler M, Basal S, Irkilata HC, Zor M, Istanbulluoglu MO, Dayanc M; Adult posterior urethral valve: a case report. Ger Med Sci. 2010;8:Doc08.

15. Jesus CM, Trindade Filho JC, Goldberg J; Late presentation of posterior urethral valve: two case reports. Sao Paulo Med J. 2008;126:126-7.

16. Mohammadjafari H, Ahangardarabi S, Shafaee S; The Long Term Prognosis of Posterior Urethral Valve in Neonate in North of Iran, a More than Ten Years' Experience from a Tertiary Referral Center. Iran J Health Sci. 2015;3:1-6

17. Kabir M, Naz M, Farooq MAA, Chowdhury TK, Chowdhury MZ, Banu T; Outcome of Prenatally Diagnosed Posterior Urethral Valve Patients - Experience from a Low Income Country. Bangla J. Endosurg. 2014;1:20-23

18. Atobatele MO, Oyinloye OI, Nasir AA, Bamidele JO; Posterior urethral valve with unilateral vesicoureteral reflux and patent urachus: A rare combination of urinary tract anomaliess. Urol Ann. 2015;7:240-3

19. Casey JT, Hagerty JA, Maizels M, Chaviano AH, Yerkes E, Lindgren BW, Kaplan WE, Meyer T, Cheng EY; Early administration of oxybutynin improves bladder function and clinical outcomes in newborns with posterior urethral valves. J Urol. 2012;188:151620.

20. Guerra L, Leonard M, Castagnetti M; Best practice in the assessment of bladder function in infants. Ther Adv Urol. 2014;6:148-64.

21. Skenazy J, Horowitz M; Alpha adrenergic blockade in neonates with posterior urethral valves. J Urol. 2012;187:e654

22. Kroll P; Pharmacotherapy for Pediatric Neurogenic Bladder. Paediatr Drugs. 2017;19:463-478.

23. Djordjevic Z, Folic MM, Zivic Z, Markovic V, Jankovic SM; Nosocomial urinary tract infections caused by Pseudomonas aeruginosa and Acinetobacter species: sensitivity to antibiotics and risk factors. Am J Infect Control. 2013;41:1182-7.

24. Opara A, Ondima L, Atipo A, Mandavo C, Mouss R, Nyanga D, Avala P, Odzébé A, Bouya P; Management of Posterior Urethral Valves about 26 Cases. Open J. Urol 2021;11:95-102.

25. Jayaweera JAAS, Reyes M; Antimicrobial misuse in pediatric urinary tract infections: recurrences and renal scarring. Ann Clin Microbiol Antimicrob. 2018;17:27.

26. Balestracci A, Montecuco M, Serviddio C, Figueredo LD, Montiel V, Torres Perez C, Puyol I, Capone MA; Role of Late DMSA Renal Scan in Detecting High-Grade Vesicoureteral Reflux. Indian J Pediatr. 2019;86:784-789.

27. Lopez Pereira P, Martinez Urrutia MJ, Espinosa L, Jaureguizar E; Long-term consequences of posterior urethral valves. J Pediatr Urol. 2013;9:590-6.

28. Fusco F, Creta M, De Nunzio C, Iacovelli V, Mangiapia F, Li Marzi V, FinazziAgrò $\mathrm{E}$;Progressive bladder remodeling due to bladder outlet obstruction: a systematic review of morphological and molecular evidences in humans. BMC Urol. 2018;18:15

29. Thomas J; Etiopathogenesis and management of bladder dysfunction in patients with posterior urethral valves. Indian J Urol. 2010;26:480-489. 
30. Veiga ML, Queiroz AP, Carvalho MC, Braga AA, Sousa AS, Barroso U Jr; Parasacral transcutaneous electrical stimulation for overactive bladder in children: An assessment per session. J Pediatr Urol. 2016;12:293.e1-293.e5.

31. Bandari B, Sindgikar SP, Kumar SS, Vijaya MS, Shankar R; Renal scarring following urinary tract infections in children. Sudan J Paediatr. 2019;19:25-30.

32. Chan EP, Wang PZT, Dave S; Valve Bladder Syndrome Associated with Posterior Urethral Valves: Natural History, Work-up, and Management. Curr Bladder Dysfunct Rep 2020;15:76-82.

33. King T, Coleman R, Parashar K; Mitrofanoff for valve bladder syndrome: effect on urinary tract and renal function. J Urol. 2014;191:1517-22.

34. European Association of Urology, https:/uroweb.org/guideline/urolithiasis/\#3 (accessed 25 August 2021)

35. Amimanan P, Tavichakorntrakool R, Fong-Ngern K, Sribenjalux P, Lulitanond A, Prasongwatana V, Wongkham C, Boonsiri P, UmkaWelbat J, Thongboonkerd V; Elongation factor $\mathrm{Tu}$ on Escherichia coli isolated from urine of kidney stone patients promotes calcium oxalate crystal growth and aggregation. Sci Rep. 2017;7:2953

36. Barr-Beare E, Saxena V, Hilt EE, Thomas-White K, Schober M, Li B, Becknell B, Hains DS, Wolfe AJ, Schwaderer AL; The Interaction between Enterobacteriaceae and Calcium Oxalate Deposits. PLoS One. 2015;10::e0139575 